\title{
PHARMACOEPIDEMIOLOGY OF ANTIRETROVIRAL DRUGS IN A TEACHING HOSPITAL IN LAGOS, NIGERIA
}

\author{
I.A OREAGBA ${ }^{1,5}$, S.O. USMAN ${ }^{1}$, S.O. OLAYEMI ${ }^{1}$, K.A OSHIKOYA ${ }^{3}$, O. OPANUGA ${ }^{2}$, T.A
} ADEYEMO $^{2,4}$, O.A. LESI ${ }^{2}$, A. N. DODOO ${ }^{6}$ AND A.S. AKANMU ${ }^{2,4}$

${ }^{1}$ Department of Pharmacology, Therapeutics and Toxicology, College of Medicine, University of Lagos, Lagos, Nigeria, 12003, ${ }^{2}$ AIDS Prevention Initiative in Nigeria (APIN) Clinic, Lagos University Teaching Hospital, Lagos, Nigeria, 12003, ${ }^{3}$ Department of Pharmacology, Lagos State University College of Medicine, Ikeja, Lagos, Nigeria, ${ }^{4}$ Department of Haematology and Blood Transfusion, University of Lagos, Lagos, Nigeria, ${ }^{5}$ National Pharmacovigilance Centre, National Agency for Food and Drug Administration and Control, Abuja, Nigeria ${ }^{6}$ Centre for Clinical Pharmacology and Therapeutics University of Ghana Medical School Accra Ghana

DOI: $h t t p: / / d x$. doi.org/10.4314/gmj.v48i4.5

Corresponding Author: Dr. Ibrahim Oreagba,

Email:oreagbai@yahoo.com

Conflict of Interest: None declared

\section{SUMMARY}

Objective: Prescribing, adherence, and adverse drug events to HAART in a large antiretroviral programme in Lagos was evaluated.

Design A retrospective 5 year open cohort study

Setting The AIDS Prevention Initiative in Nigeria (APIN) clinic at LUTH is one of the United States Presidential Emergency Plan for AIDS Relief (PEPFAR) funded centers for HIV relief program in Nigeria Participants The case files of 390 patients on HAART and attending the APIN clinic were reviewed sequel to random selection.

Main outcome measures: Demographics of the patients and pattern of antiretroviral (ARV) combination drugs prescribed were extracted from their case files. The details of the adverse drug events (ADEs) were extracted from drug toxicity forms regularly filled for each patient. A Chi-square test with Yates correction was used to determine the association between adherence and therapeutic outcome

Results A total of 2944 prescriptions were assessed. Zidovudine + lamivudine + nevirapine $(35.87 \%)$ and stavudine + lamivudine + nevirapine $(35.63 \%)$ were the most frequently prescribed combinations. Over 2000 ADEs were reported with cough (13.3\%), fever $(8.75 \%)$ and skin rashes $(8.01 \%)$ being the most frequently reported. Drug adherence was associated with good therapeutic outcome $(\chi 2=115.60, \mathrm{p}<0.0001)$. Conclusions: Zidovudine + lamivudine + nevirapine was the most frequently prescribed ARV combination. Cough was the most frequently reported ADE. Interventions aimed at rational prescribing of ARV drugs and improving adherence to antiretroviral drugs is essential for good therapeutic outcome in the treatment of HIV infection.
Keywords: Pharmacoepidemiology, antiretroviral drugs, drug adherence, adverse events

\section{INTRODUCTION}

Infection with Human Immunodeficiency Virus (HIV) and its progression to Acquired Immunodeficiency Syndrome (AIDS) have been a global crisis and a big challenge plaguing the healthy living of human today. It erodes both social and economic development as a result of its great influence on family stability, life expectancy and economic development. ${ }^{1}$ The burden is high globally as it remains the greatest health crisis facing the world today. There are approximately 34 million people currently living with HIV and nearly 30 million people have died of AIDS-related causes since the beginning of the epidemic., ${ }^{2,3}$ The highest proportion of people living with HIV (97\%) resides in lowand middle-income countries, particularly in subSaharan Africa. ${ }^{4}$

The use of highly active antiretroviral therapy (HAART) has resulted in a significant reduction in the morbidity and mortality related to AIDS. HAART is defined as the concurrent use of a combination of three or more ARV drugs to suppress HIV replication. It represents the current standard of care of antiretroviral therapy (ART) for HIV-infected patients. ${ }^{5}$ This strategy evolved from the recognition that treatment of chronic HIV infection with only one or two ARV drugs may result in rapid treatment failure and the development of resistance to the ARV drugs, which may compromise future therapeutic options. ${ }^{5,6}$ About a quarter of patients on ART discontinued the treatment within the first eight months due to treatment failure, adverse drug toxicity or non-compliance with the therapy. ${ }^{7,8}$ 
There is also abundant evidence indicating that treatment success is dependent on adherence to ARV drugs. ${ }^{9,10}$ However, adverse toxicity of the ARV drugs has been reported to also impart negatively on adherence to treatment. ${ }^{9-11}$

It is, therefore, necessary that clinicians have a clear understanding of the potential adverse effects of the ARV drugs. In addition, they should be able to readily recognise adverse effects in patients and manage them effectively. The risk of specific adverse effects varies from one ARV drug to another, from one drug class to another, and from one patient to another. ${ }^{12}$ The spectrum of adverse effects associated with ARVs may also vary between developed and developing countries. ${ }^{13}$

The nucleoside reverse transcriptase inhibitors (NRTIs) are associated with lactic acidosis, lipodystrophy, and hyperlipidemia ${ }^{9,11}$, while the non-nucleoside reverse transcriptase inhibitors (NNRTIs) are associated with neuropsychiatric symptoms, rash, liver toxicity, and lipid abnormalities. ${ }^{11}$ Protease inhibitors (PIs) are associated with gastrointestinal intolerance and glucose and lipid abnormalities 9 . The entry inhibitor (maraviroc) and the integrase inhibitor (raltegravir) are new drugs used for treatment-naive and treatment-experienced patients. Maraviroc is associated with bronchitis, nasopharyngitis, and esophageal candidiasis, while raltegravir is associated with increased risk of myopathy and rhabdomyolysis. ${ }^{14}$

There have been reports of adverse events to specific ARV drugs which include peripheral neuropathy and lipodystrophy associated with stavudine ${ }^{10,15}$, anaemia associated with zidovudine ${ }^{16,17}$, and nevirapine based hepatotoxicity and rash $^{9,18-20}$. The incidence of hepatotoxicity has been reported as $8 \%$ and $16 \%$ for patients on efavirenz (EFV) and nevirapine (NVP), respective$1 y^{20}$, while the incidence of anaemia associated with zidovudine ranged from $3-12 \%$ in developing countries. $^{13}$

As a means of improving adherence to ARV drugs, newer ones are available as fixed- dose combination ${ }^{21}$. Despite the decreased pill counts and frequency of dosing per day for usual starting regimens, ART continue to have significant adverse effects that require monitoring for drug interactions and long-term morbidity related to cardiovascular, dermatological, bone, musculoskeletal and kidney disease. ${ }^{22}$ Most clinical trials have a relatively short follow-up duration and can underestimate longer term complications of therapy.

A six years follow-up of patients in a Swiss Cohort study showed the presence of laboratory adverse events that was associated with higher rates of mortality, highlighting the importance of adverse events in overall patient management. ${ }^{23}$

Several factors may predispose individuals to adverse effects of ARV drugs. Females appear to have a higher risk than male to develop Stevens-Johnson syndrome, rashes, and hepatotoxicity from NVP. ${ }^{24,25}$ Females are also at higher risk than males to develop lactic acidosis from NRTIs. ${ }^{26,27}$ Other risk factors include concomitant use of medications with overlapping and additive toxicities; comorbid conditions that may increase the risk of or exacerbate adverse effects such as alcoholism ${ }^{28}$ or co-infection with viral hepatitis, which may increase risk of hepatotoxicity ${ }^{20}$; drug-drug interactions that may lead to an increase in drug toxicities; or genetic factors predisposing patients to abacavir (ABC) hypersensitivity reaction. ${ }^{29}$

Although the therapeutic goals of ART include achieving and maintaining viral suppression and improving immune function, an overall goal should be to select a regimen that is not only effective but also is safe. This requires consideration of not only the toxicity potential of the ARV drugs but also an individual patient's underlying conditions, concomitant medications, and prior history of drug intolerances.

Given the paucity of data on the use and reporting of the adverse effects of ARV drugs in HIV-infected adults in Nigeria, we aimed to determine the prescribing pattern of ARV drugs used at the AIDS Prevention Initiative in Nigeria (APIN) clinic, LUTH. In addition, we also determined the levels of adherence to the drugs, and the associated adverse effects.

\section{METHOD}

\section{Study design}

We retrospectively analysed the clinical records of HIV-infected adults who were receiving treatment at the AIDS Prevention Initiative in Nigeria (APIN) clinic at the Lagos University Teaching Hospital (LUTH) in Nigeria, between January 2005 and June 2009. The APIN clinic at LUTH is one of the United States' Presidential Emergency Plan for AIDS Relief-funded centres for the HIV relief program. The clinic is held every Monday through Friday, between 8 am and 4 pm.

An average of 250 old and new patients (adults and children) is attended to daily at the APIN clinic. The ARV drugs are dispensed free of charge, on monthly basis, to about 8,000 registered HIV infected patients including men, pregnant and non-pregnant women and children from different parts of Nigeria. 
Only adult patients (male and female) were included in this study. Other inclusion criteria were patient older than 12 years, non-pregnant women, confirmed HIVinfection with western blot test, patients with or without AIDS presentation according to the criteria set out by the World Health Organization (WHO). ${ }^{30}$

Patient must have been enrolled on ART only at the APIN clinic, LUTH and they must have used ARV drugs, at least once, after enrolment. Patients must also have completely documented demographic information and prescribed medications in the case files. Patients who died during the course of treatment, stopped or changed treatment were also included in the study.

Children and pregnant women are special population group that were excluded. Patients who were transferred to other hospitals, or had multiple co-morbidities and concomitant prescription of drugs with potential adverse interactions (rifampicin, clarithromycin, fluconazole, and ketoconazole) with the recommended ARV drugs, were also excluded. The morbid conditions included tuberculosis, cancer, diabetes and other medical conditions. We equally excluded the patients who were not willing to participate in the study.

\section{Sample Size determination}

Raosoft $\AA$ sample size calculator was used to determine the sample size ${ }^{31}$. A sample size of 367 was calculated from the 8000 population of registered patients on ARV drugs using 5\% error margin at $95 \%$ confidence interval, assuming $50 \%$ of the patients have all the measured outcomes documented in their case files. However, a sample size of 390 patients was used for ease of data analysis.

\section{Data abstraction}

Eligible cases were identified through the main register obtained from the medical record of the APIN clinic. Each patient was assigned an identification number and the case file randomly selected using a web-based random sampling method. One of the researchers reviewed each case file, and-using a standard form purposely designed for the study-extracted data on the demographics, concurrent infections at first presentation and follow-up, co-prescribed drugs, and the ART regimen prescribed. Other important information extracted included the results of routine immunological, virological and haematological investigations at baseline and follow-up. We also extracted information on the relevant clinical signs and symptoms recorded before and after the commencement of ART. Documented adverse drug events were also extracted from the case files.
Data initially extracted were corroborated by two other researchers (a clinical pharmacist and a clinical pharmacologist with medical background). There was $85 \%$ agreement between the three reviewers using Kappa statistics. The opinion of a fourth reviewer (a clinical pharmacologist with pharmacy background), however, superseded in those areas of disagreement.

\section{Prescribed ART regimen}

The national guidelines for HIV treatment in Nigeria recommended first-line ARV drugs for adults as zidovudine (AZT) or tenofovir (TDF) with lamivudine (3TC) or emtricitabine (FTC) and nevirapine (NVP) or efavirenz $(\mathrm{EFV})^{32}$. Second-line ARV drugs were recommended when there was therapeutic failure or severe adverse effects to the first line combination. The regimens included AZT-3TC or FTC and TDF or didanosine (ddI) or abacavir (ABC) plus lopinavir/ritonavir (LPV/r). The prescribed ARV drugs that were outside of those recommended by the WHO or national guidelines were considered as others.

\section{Adherence and treatment failure}

Adherence was defined according to the method of Arnsten et al. $^{33}$ (the percentage of doses taken as prescribed). It was measured by expressing the number of doses taken as a percentage of the total number of doses prescribed. For example if 20 doses were prescribed and 19 doses were taken by a patient, the adherence is $95 \%$. This translates to missing one dose in ten days on a twice daily regimen. The number of doses taken was determined, during each month's drug pickup through three days preceding clinic visit recall. Adherence was considered good when it was $95 \%$ and above or poor when it was below $95 \%$.

The adherence levels were correlated with therapeutic outcome through laboratory measurement of $\mathrm{CD}^{+}$cell count and viral load. Therapeutic outcome was good when the $\mathrm{CD}^{+}$cell count increased by at least 50 to 100 cells/dL and the viral load was reduced to undetectable level within 3 to 6 months of commencing ARV therapy ${ }^{34}$. Virological failure occurred when the viral load failed to reduce to undetectable level within 3 to 6 months of commencement of HAART and when the CD4+ cell count did not increase by at least 50 cells /dL within same period this was considered immunological failure.

\section{Data analysis}

The major outcomes measured were the types and frequency of ART regimens prescribed, adherence to treatments, and the types and frequency of adverse events to the ARV drugs experienced by the patients. Data were analyzed using simple descriptive statistics. 
A Chi-square test with Yates correction was used to determine an association between adherence and therapeutic outcome at a $5 \%$ level of significance.

\section{Ethical considerations}

The research protocol was reviewed and approved by the Research and Ethics Committee of LUTH..

\section{RESULTS}

\section{Socio-demographic characteristics}

The records of 390 eligible patients were reviewed in this study. The median age of the patients was 32 (range 13-67) years, while the mean age was 35years (sd 9.67). The socio-demographics of the patients are as presented in Table 1.

\section{Prescribed ART regimes}

A total of 2944 prescriptions were reviewed and 23 different ARV drug combinations were prescribed.

The patterns of ART regimens prescribed at the clinic are presented in Table 2 . The most frequently pre- scribed regimen was AZT-3TC-NVP, followed by D4T-3TC-NVP

Table 1 Socio-demographic characteristics of participants

\begin{tabular}{|c|c|c|}
\hline Variable & $\begin{array}{l}\text { Frequency } \\
(n=390)\end{array}$ & $\%$ \\
\hline \multicolumn{3}{|l|}{ Gender } \\
\hline Male & 144 & 37.00 \\
\hline Female & 246 & 63.00 \\
\hline \multicolumn{3}{|c|}{ Educational status } \\
\hline None & 23 & 6.00 \\
\hline Primary & 86 & 22.00 \\
\hline Secondary & 152 & 39.00 \\
\hline Post-secondary & 129 & 33.00 \\
\hline \multicolumn{3}{|l|}{ Marital status } \\
\hline Married & 246.0 & 63.00 \\
\hline Single & 92.0 & 24.00 \\
\hline Widowed & 21.0 & 5.00 \\
\hline Divorced & 15.0 & 4.00 \\
\hline Separated & 8.0 & 2.10 \\
\hline Undocumented & 8.0 & 2.00 \\
\hline
\end{tabular}

Table 2 Different Antiretroviral Drug Combinations and their Frequency of Prescription

\begin{tabular}{|c|c|c|c|c|}
\hline $\mathbf{S} / \mathbf{N}$ & $\begin{array}{l}\text { Antiretroviral Drug (HAART) } \\
\text { Combinations }\end{array}$ & $\begin{array}{l}\text { Number } \\
\text { of patients }\end{array}$ & $\begin{array}{l}\text { Total Number of each } \\
\text { HAART prescriptions }\end{array}$ & $\begin{array}{l}\text { Percentage of each } \\
\text { HAART Combination }\end{array}$ \\
\hline 1 & $\mathrm{AZT} / 3 \mathrm{TC} / \mathrm{NVP}$ & 145 & 1056 & 35.87 \\
\hline 2 & $\mathrm{D} 4 \mathrm{~T} / 3 \mathrm{TC} / \mathrm{NVP}$ & 94 & 1049 & 35.63 \\
\hline 3 & $\mathrm{AZT} / 3 \mathrm{TC} / \mathrm{EFV}$ & 32 & 223 & 7.57 \\
\hline 4 & $\mathrm{AZT} / 3 \mathrm{TC} / \mathrm{NVP} / \mathrm{LPV} / \mathrm{r}$ & 16 & 135 & 4.59 \\
\hline 5 & FTC/ TDF / NVP & 2 & 99 & 3.36 \\
\hline 6 & FTC / TDF / EFV & 22 & 76 & 2.58 \\
\hline 7 & $\mathrm{DDI} / 3 \mathrm{TC} / \mathrm{NVP}$ & 9 & 63 & 2.14 \\
\hline 8 & $\mathrm{FTC} / \mathrm{TDF} / \mathrm{AZT} / \mathrm{LPV} / \mathrm{r}$ & 7 & 49 & 1.66 \\
\hline 9 & $\mathrm{DDI} / 3 \mathrm{TC} / \mathrm{EFV}$ & 5 & 36 & 1.22 \\
\hline 10 & $\mathrm{D} 4 \mathrm{~T} / 3 \mathrm{TC} / \mathrm{EFV}$ & 7 & 34 & 1.15 \\
\hline 11 & $\mathrm{AZT} / 3 \mathrm{TC}$ & 11 & 29 & 0.99 \\
\hline 12 & $\mathrm{AZT} / 3 \mathrm{TC} / \mathrm{LPV} / \mathrm{r}$ & 2 & 21 & 0.71 \\
\hline 13 & $\mathrm{FTC} / \mathrm{TDF} / \mathrm{SQV} / \mathrm{r}$ & 4 & 20 & 0.68 \\
\hline 14 & $\mathrm{FTC} / \mathrm{TDF} / \mathrm{LPV} / \mathrm{r}$ & 1 & 7 & 0.24 \\
\hline 15 & $\mathrm{D} 4 \mathrm{~T} / 3 \mathrm{TC} / \mathrm{IDV} / \mathrm{r}$ & 1 & 7 & 0.24 \\
\hline 6 & $\mathrm{IDV} / \mathrm{AZT} / 3 \mathrm{TC}$ & 1 & 1 & 0.03 \\
\hline 17 & $\mathrm{ABC} / 3 \mathrm{TC} / \mathrm{SQV} / \mathrm{r}$ & 1 & 6 & 0.20 \\
\hline 18 & $\mathrm{ABC} / \mathrm{DDI} / \mathrm{LPV} / \mathrm{r}$ & 1 & 6 & 0.20 \\
\hline 19 & $\mathrm{TDF} / 3 \mathrm{TC} / \mathrm{SQV} / \mathrm{r}$ & 1 & 6 & 0.20 \\
\hline 20 & $\mathrm{AZT} / 3 \mathrm{TC} / \mathrm{SQV} / \mathrm{r}$ & 2 & 14 & 0.48 \\
\hline 21 & $\mathrm{AZT} / 3 \mathrm{TC} / \mathrm{NVF}$ & 1 & 3 & 0.10 \\
\hline 22 & $\mathrm{ENF} / \mathrm{r} / \mathrm{DRV} / \mathrm{SQV} / \mathrm{TDV}$ & & 2 & 0.07 \\
\hline \multirow[t]{2}{*}{23} & $\mathrm{ABC} / 3 \mathrm{TC} / \mathrm{EFV}$ & 1 & 2 & 0.07 \\
\hline & TOTAL & & 2944 & 100.00 \\
\hline
\end{tabular}

Abbreviations: Stavudine (D4T); Lamivudine (3TC); zidovudine (AZT); Efavirence (EFV); Tenofovir (TDF); Lopinavir/ritonavir (LPV/r); Saquinavir (SQV); Enfuvirtide (ENF);
Abacavir (ABC); Darunavir (DRV); Didanosine (DDI); Indinavir (IDV); Nelfinavir (NVF); Emtricitabine (FTC) 


\section{Adherence and therapeutic outcome}

The majority of the patients $(75 \%)$ with good adherence had good therapeutic outcome and almost all $(95 \%)$ of those who adhered poorly had therapeutic failure. Subjecting this to chi square analysis showed that drug adherence was associated with good therapeutic outcome $\left(\chi^{2}=115.60, p<0.0001\right)$. Table 3 shows the association between adherence and therapeutic outcome.

Table 3 Relationship between Adherence and Therapeutic outcome

\begin{tabular}{|l|l|l|l|l|}
\hline Adherence & $\begin{array}{l}\text { Good Thera- } \\
\text { peutic } \\
\text { Outcome } \\
\text { Frequency (n) }\end{array}$ & $\begin{array}{l}\text { Therapeutic } \\
\text { Failure } \\
\text { Frequency (n) }\end{array}$ & Total & p- value \\
\hline Poor & $3(5 \%)$ & $54(95 \%)$ & $57(14.6 \%)$ & \\
\hline Good & $261(78 \%)$ & $72(22 \%)$ & $333(85.4 \%)$ & \\
\hline Total & $264(68 \%)$ & $126(32 \%)$ & $390(100 \%)$ & $<0.0001$ \\
\hline
\end{tabular}

Adverse events associated with ARV drugs

The adverse events associated with the use of the various ARV drugs are summarized in Table 4.
Only complaints or ailments that developed or were observed in each of the patients after the commencement of therapy of a particular combination of antiretroviral drugs were included. A total of 90 different adverse events were recorded ranging from minor symptoms such as rash and catarrh to serious ones such as hepatomegaly and death.

The latter occurred in three patients one of whom took a combination of stavudine-lamivudine-nevirapine while the other two took a combination of zidovudinelamivudine-nevirapine. Table 4 showed the frequently reported adverse events to the ARV drugs with cough (13.3\%), fever $(8.75 \%)$, and skin rashes $(8.01 \%)$ being the most frequently reported adverse events.

Very few reports were made on several other adverse events including known and common adverse events to ARV drugs such as peripheral neuropathy (1.78\%), nausea and vomiting $(2.57 \%)$, anaemia and lipoatrophy $(0.4 \%)$.

Table 4 Adverse Drug Events of Antiretroviral Drug Combinations at LUTH PEPFAR Clinic.

\begin{tabular}{|c|c|c|c|c|c|c|c|c|c|}
\hline \multirow[b]{2}{*}{ Organ System* } & \multicolumn{9}{|c|}{ Frequency of reports from different ARV combinations } \\
\hline & $\begin{array}{l}\text { AZT } \\
3 \text { TC } \\
\text { NVP }\end{array}$ & $\begin{array}{l}\text { D4T } \\
\text { 3TC } \\
\text { NVP }\end{array}$ & $\begin{array}{l}\text { AZT } \\
3 T C \\
\text { EFV }\end{array}$ & $\begin{array}{l}\text { FTC } \\
\text { TDF } \\
\text { NVP }\end{array}$ & $\begin{array}{l}\text { AZT } \\
3 \mathrm{TC} \\
\mathrm{NVP} \\
\mathrm{LPV} / \mathrm{r}\end{array}$ & $\begin{array}{l}\text { FTC } \\
\text { TDF } \\
\text { EFV }\end{array}$ & ${ }^{\#}$ OTHERS & TOTAL & $\%$ \\
\hline $\begin{array}{l}\text { Gastro-intestinal system disorders } \\
(0600)\end{array}$ & 108 & 57 & 3 & - & - & - & 11 & 179 & $8.85 \%$ \\
\hline Abdominal pain & 12 & 17 & - & - & - & - & 4 & 33 & $1.63 \%$ \\
\hline Nausea and vomiting & 35 & 7 & 3 & - & - & - & 7 & 52 & $2.57 \%$ \\
\hline Diarrhoea & 61 & 33 & - & - & - & - & - & 94 & $4.65 \%$ \\
\hline $\begin{array}{lll}\begin{array}{l}\text { Respiratory } \\
\text { ders }(1100)\end{array} & \text { system } & \text { disor- } \\
\end{array}$ & 107 & 88 & 39 & 34 & 8 & 27 & 65 & 368 & $18.20 \%$ \\
\hline Catarrh / runny nose & 30 & 8 & - & 8 & - & - & 11 & 57 & $2.82 \%$ \\
\hline Nasal congestion & 8 & 8 & 13 & - & - & - & 13 & 42 & $2.08 \%$ \\
\hline Cough & 69 & 72 & 26 & 26 & 8 & 27 & 41 & 269 & $13.30 \%$ \\
\hline $\begin{array}{l}\text { Central and peripheral nervous } \\
\text { system disorders }(041)\end{array}$ & 119 & 120 & 78 & 44 & - & 20 & 154 & 535 & $25.66 \%$ \\
\hline Fatigue & 26 & 52 & 19 & 7 & - & - & 33 & 137 & $6.77 \%$ \\
\hline Fever & 58 & 29 & 25 & 8 & - & 4 & 53 & 177 & $8.75 \%$ \\
\hline Headache & - & 7 & 14 & 14 & - & 4 & 29 & 68 & $3.36 \%$ \\
\hline Anorexia & 15 & 8 & 4 & - & - & 4 & 19 & 50 & $2.57 \%$ \\
\hline Malaise & 20 & 20 & 13 & 13 & - & 6 & 13 & 85 & $4.21 \%$ \\
\hline Organ System* & $\begin{array}{l}\text { AZT } \\
3 \mathrm{TC} \\
\mathrm{NVP}\end{array}$ & $\begin{array}{l}\text { D4T } \\
3 \mathrm{TC} \\
\text { NVP }\end{array}$ & $\begin{array}{l}\text { AZT } \\
3 \mathrm{TC} \\
\text { EFV }\end{array}$ & $\begin{array}{l}\text { FTC } \\
\text { TDF } \\
\text { NVP }\end{array}$ & $\begin{array}{l}\text { AZT } \\
\text { 3TC } \\
\text { NVP } \\
\text { LPV/r }\end{array}$ & $\begin{array}{l}\text { FTC } \\
\text { TDF } \\
\text { EFV }\end{array}$ & ${ }^{\#}$ OTHERS & TOTAL & $\%$ \\
\hline $\begin{array}{l}\text { Muscular-skeletal system disor- } \\
\text { ders }(0200)\end{array}$ & 113 & 54 & 27 & 19 & 5 & 5 & 16 & 239 & $11.81 \%$ \\
\hline
\end{tabular}




\begin{tabular}{|c|c|c|c|c|c|c|c|c|c|}
\hline \multirow[b]{2}{*}{ Organ System* } & \multicolumn{9}{|c|}{ Frequency of reports from different ARV combinations } \\
\hline & $\begin{array}{l}\text { AZT } \\
3 \mathrm{TC} \\
\text { NVP }\end{array}$ & $\begin{array}{l}\text { D4T } \\
\text { 3TC } \\
\text { NVP }\end{array}$ & $\begin{array}{l}\text { AZT } \\
3 \mathrm{TC} \\
\text { EFV }\end{array}$ & $\begin{array}{l}\text { FTC } \\
\text { TDF } \\
\text { NVP }\end{array}$ & $\begin{array}{l}\text { AZT } \\
3 \mathrm{TC} \\
\mathrm{NVP} \\
\mathrm{LPV} / \mathrm{r}\end{array}$ & $\begin{array}{l}\text { FTC } \\
\text { TDF } \\
\text { EFV }\end{array}$ & "OTHERS & TOTAL & $\%$ \\
\hline Joint pain & 15 & 22 & 3 & 2 & - & - & 2 & 44 & $2.17 \%$ \\
\hline Body aches & 79 & 15 & 19 & 15 & - & 5 & 9 & 142 & $7.02 \%$ \\
\hline Chest pain & 19 & 17 & 5 & 2 & 5 & - & 5 & 53 & $2.62 \%$ \\
\hline Cardiovascular disorders $(1010$ & - & 25 & - & - & - & - & 9 & 34 & $1.68 \%$ \\
\hline Hypertension & - & 25 & - & - & - & - & 9 & 34 & $1.68 \%$ \\
\hline $\begin{array}{l}\text { Skin and appendages disorders } \\
(0100)\end{array}$ & 155 & 25 & 21 & - & 4 & - & 60 & 265 & $13.10 \%$ \\
\hline Itchy skin & 61 & 4 & 11 & - & 4 & - & 23 & 103 & $5.09 \%$ \\
\hline Skin rashes & 94 & 21 & 10 & - & - & - & 37 & 162 & $8.01 \%$ \\
\hline Special senses disorders $(0433)$ & 15 & 5 & 5 & - & - & - & 11 & 36 & $1.78 \%$ \\
\hline $\begin{array}{l}\text { Pain and numbness in hands and } \\
\text { feet }\end{array}$ & 15 & 5 & 5 & - & - & - & 11 & 36 & $1.78 \%$ \\
\hline $\begin{array}{l}\text { Body as a whole - general disor- } \\
\text { der(1810) }\end{array}$ & 31 & 5 & - & - & 4 & 3 & 12 & 59 & $1.34 \%$ \\
\hline Death & 2 & 1 & - & - & - & - & - & 3 & $0.15 \%$ \\
\hline Weight loss & 10 & 4 & - & - & 4 & 3 & 3 & 24 & $1.19 \%$ \\
\hline SUBTOTAL & 633 & 375 & 170 & 95 & 25 & 53 & 331 & 1682 & $82.42 \%$ \\
\hline OTHERS** & 127 & 86 & 29 & 17 & 4 & 11 & 67 & 341 & $16.74 \%$ \\
\hline TOTAL & 760 & 461 & 199 & 112 & 29 & 64 & 398 & 2023 & $100.00 \%$ \\
\hline
\end{tabular}

\section{NOTES}

*WHO-ART Classification system code

**Others: Abdominal enlargement $(0.89 \%)$, alopecia $(0.10 \%)$, amenorrhoea $(0.54 \%)$, amnesia $(0.05 \%)$, anaemia $(0.15 \%)$, anal lesion $(0.30 \%)$, anxiety $(0.05 \%)$, aphakia $(0.05 \%)$, bitter taste $(0.59 \%)$, blurred vision $(0.15 \%)$, boil $(0.69 \%)$, breast reduction $(0.05 \%)$, breast enlargement $(0.10 \%)$, cheilitis $(0.05 \%)$, chills $(0.05 \%)$, constipation $(0.15 \%)$, cracked lips $(0.15 \%)$, crepitation $(0.10 \%)$, decreased libido $(0.15 \%)$, dizziness $(0.44 \%)$, dyspepsia $(0.10 \%)$, dyspnea $(0.05 \%)$, ear ache $(0.30 \%)$, eye pain $(0.05 \%)$, eye redness $(0.25 \%)$, eye itching $(0.05 \%)$, genital wart $(0.02 \%)$, hemiparesis $(0.40 \%)$, heartburn $(0.25 \%)$, insomnia $(0.89 \%)$, lipodystrophy $(0.15 \%)$, lymphadenopathy $(0.84 \%)$, malaise $(4.21 \%)$, mouth ulcer $(0.30 \%)$, myalgia ( $0.05 \%)$, nephropathy $(0.05 \%)$, nocturia $(0.30 \%)$, obesity $(0.35 \%)$, oral thrush $(0.40 \%)$, palpitation $(0.02 \%)$, paraesthesia $(0.20 \%)$, pedal oedema $(0.74 \%)$, polyuria $(0.10 \%)$, rigors $(0.59 \%)$, scarring of the cornea $(0.05 \%)$, seizures $(0.10 \%)$, shortness of breadth $(0.44 \%)$, skin discoloration $(0.05 \%)$, sore throat $(0.50 \%)$, sore gum $(0.35 \%)$, splenomegally $(0.15 \%)$, tachycardia $(0.05 \%)$, tachypnea $(0.05 \%)$, toothache $(0.20 \%)$, toxoplasmosis $(0.10 \%)$, urinary frequency $(0.40 \%)$, painful urination $(0.40 \%)$

Vaginal discharge $(0.04 \%)$, vagina itching $(0.74 \%)$, wrist swelling $(0.05 \%)$

\#Others: (7) DDI / 3TC / NVP, (8) FTC / TDF / AZT / LPV / r (9) $\mathrm{DDI} / 3 \mathrm{TC} / \mathrm{EFV}$, (10) D4T / 3TC / EFV, (11) AZT/3TC, (12) $\mathrm{AZT} / 3 \mathrm{TC} / \mathrm{LPV} / \mathrm{r}$, (13) FTC/TDF/SQV/r, (14) FTC/TDF/LPV/r, (15) $\mathrm{D} 4 \mathrm{~T} / 3 \mathrm{TC} / \mathrm{IDV} / \mathrm{r}$, (16) IDV/AZT/3TC, (17) $\mathrm{ABC} / 3 \mathrm{TC} / \mathrm{SQV} / \mathrm{r}$, (18) $\mathrm{ABC} / \mathrm{DDI} / \mathrm{LPV} / \mathrm{r},(19) \mathrm{TDF} / 3 \mathrm{TC} / \mathrm{SQV} / \mathrm{r},(20) \mathrm{AZT} / 3 \mathrm{TC} / \mathrm{SQV} / \mathrm{r}$, (21) $\mathrm{AZT} / 3 \mathrm{TC} / \mathrm{NVF}$, (22) $\mathrm{ENF} / \mathrm{r} / \mathrm{DRV} / \mathrm{SQV} / \mathrm{TDV}$ and (23) $\mathrm{ABC} / 3 \mathrm{TC} / \mathrm{EFV}$.
Stavudine (D4T); Lamivudine (3TC); zidovudine (AZT); Efavirence (EFV); Tenofovir (TDF); Lopinavir/ritonavir (LPV/r)

Saquinavir (SQV); Enfuvirtide (ENF); Abacavir (ABC); Darunavir (DRV); Didanosine (DDI); Indinavir (IDV); Nelfinavir (NVF); Emtricitabine (FTC) Tenofovir (TDF); Lopinavir/ritonavir (LPV/r)

\section{DISCUSSION}

This study highlighted the major ARV drug combinations prescribed at APIN Clinic, LUTH, in Nigeria and the adverse events associated with their use. These adverse events are well characterized and known to be associated with the combinations given. The most frequently prescribed combinations were AZT-3TC-NVP and D4T-3TC-NVP. These combinations and others prescribed are consistent with the guidelines of the WHO. ${ }^{30}$

The combinations are also in keeping with the recommendations of the National guidelines for the use of ARV drugs in Nigeria. ${ }^{32}$ However the use of 23 different ARV drug combinations in a single clinic did not reflect rational prescribing and was in contrast to the National treatment guidelines. ${ }^{32}$

A closer look at these combinations revealed that less than $10 \%$ of them were due to treatment switches resulting from treatment failure or drug related toxicities. 
This irrational prescribing would suggest a need for training and re-training of the doctors on rational pharmacotherapeutics of ARV drugs.

The combination of AZT-3TC-EFV regimen, though recommended by the national guidelines, was less frequently prescribed probably because of intolerance to EFV and its contraindication in pregnancy. ${ }^{35}$

Majority of the patients were females, in their reproductive ages, and are likely to get pregnant during their course of treatment. This may be the reason why an EFV-based ART was avoided in the patients.

The preponderance of female patients (in their reproductive ages) afflicted with HIV in this study is in agreement with the United Nations report that over half of the 33.3 million people estimated to be living with HIV and AIDS at the end of year 2009 were women. ${ }^{36}$ Also, in Nigeria, HIV gender statistics in 2009 revealed that for age above 15 years, the prevalence was higher in women $(52 \%)$ than in men $(37 \%)$ and children $(11 \%){ }^{37}$ Given that most often, the patients were literate, it will be appropriate to incorporate sex education and enlightenment campaign against HIV, directed more towards the female gender by the Federal Ministry of Health, into HIV/AIDS preventive measures in Nigeria.

Medication adherence is a sine qua non for good therapeutic outcome in the management of HIV/AIDS infection with antiretroviral drugs. According to the National treatment guideline, for a good therapeutic outcome, viral load should be reduced to undetectable levels and $\mathrm{CD}^{+}$cell counts should increase by a minimum of 100 cells $/ \mathrm{mm}^{3}$ in a year. ${ }^{32}$ This should produce an accelerated response after three months of commencement of ART. Any result outside these values will amount to therapeutic failure which could manifest as immunological failure, virological failure or both. ${ }^{38}$ Virological failure occurs when the viral load is still detectable after 3 to 6 months of antiretroviral therapy while immunological failure is said to occur if the $\mathrm{CD} 4^{+}$cell counts fail to increase by, at least, 50 to 100 cells $/ \mathrm{mm}^{3}$ after 6 months to one year of antiretroviral therapy. ${ }^{38}$

Our findings revealed a statistically significant association between drug adherence and good therapeutic outcome. For a quarter of the patients who were assessed to have adhered adequately and still had therapeutic failure, drug resistance could be responsible for this.

There is, therefore, a need to undertake resistance studies in these patients since such a high level of re- sistance in patients on ART should ring alarm bells globally. A similar result was obtained in a study performed in Brazil in which some patients had therapeutic failure despite adequate adherence to ART regimen. $^{38}$

As a result, the choice of subsequent therapies proved to be difficult, since such failure generally resulted in the emergence of resistant mutations that could even cause cross-resistance between several ARV drugs of the same class. In this scenario, several studies have assessed the benefit of genotyping tests as a tool for assisting in the therapeutic rescue of patients with treatment failure. ${ }^{39}$ These studies have shown that, among patients with treatment failure, the use of genotyping tests led to a greater effectiveness regarding medication change, in comparison with the empirical choices that were habitually made. ${ }^{39}$

The fact that patients may not truly disclose the number of doses of ARV drugs they have missed may also account for the therapeutic failure in this study since adherence was assessed through recall. As for those who adhered poorly, the complexity of ART regimens, whether due to pill number, dosing frequency, meal restrictions or other issues along with adverse drug events such as lip dystrophy, dyslipidemia, insulin resistance and a host of others may create intentional non-adherence and may have contributed to this problem. ${ }^{39}$

Cough $(13.3 \%)$ was the most frequently reported adverse event associated with the use of ARV drugs. Except for maraviroc, an HIV entry inhibitor, cough has not been reported as a common adverse event of ARV drugs ${ }^{40}$ and in this study none of the patients was on maraviroc because it was not among the 23 different regimens prescribed. The cough was unlikely due to tuberculosis as patients with this comorbidity were excluded. Cough could also be a symptom of advanced HIV infection rather than being an adverse event of ARV drugs. An evidence supporting this is found in a study carried out in India in which cough $(72.1 \%)$ was the second most common presenting symptom after weight loss $(74.4 \%)$ in drug- naive AIDS patients. ${ }^{41}$

Because cough is not a well-documented adverse event to the prescribed ARV drugs in this study, it is difficult to identify the specific ARV drug responsible for this in a retrospective study. This will be the basis for a prospective study where causality between each ART regimen and cough can be adequately assessed. The prevalence of fever and rashes were considerable in this study. This could be due to the fact NVP-based ART regimen was the most frequently prescribed. 
Rash is a common adverse event associated with NVP and other NNRTIs. ${ }^{40}$

A few medications can cause fever but it is considered an adverse effect of ARV drug if the fever was accompanied by a rash. Fever and rash are symptoms of hypersensitivity reactions to some ARV drugs especially DRV and ABC. ${ }^{42}$ Only very few of the well-known and common adverse effects of ARV drugs such as lip dystrophy, peripheral neuropathy, nausea and vomiting were reported in this study. Patients with poor adherence are more likely to report adverse drug events since these could contribute to their poor adherence status.

\section{Limitations}

One of the limitations of this study was lack of adequate information on certain risk factors for adverse events. For example, data was not obtained on comorbid conditions like tuberculosis as stated earlier. A prospective study involving recruitment of patients and long term follow up after initiation of ART would have provided more information and permitted more extensive follow up. These would have allowed a better case causality assessment for any of the adverse events. Another limitation was incomplete laboratory data for many of the patients.

Apart from viral load and $\mathrm{CD}^{+}$cell counts, other laboratory tests results like liver function test, creatinine clearance, lipid profiles and blood sugar level were not extracted for analysis because data were not available. Therefore, adverse events reported were mainly clinical. Furthermore some of the suspected ADEs reported were similar to the symptoms and signs of HIV/AIDS which further reinforces the need to report the clinical stages at presentation and/or enrolments. Patients on concomitant antimalarial medication (artemisinin-based combination therapy) were not excluded because of the burden of malaria in Nigeria. This group of drugs is known theoretically to interact adversely with ARV drugs ${ }^{43}$ and may have probably contributed to the observed adverse events.

\section{CONCLUSION}

A combination of AZT-3TC-NVP was the most frequently prescribed ARV drugs in APIN clinic, LUTH. Many of the ART regimens prescribed were outside the WHO and national guidelines for HIV/AIDS treatment, suggesting an irrational prescription. Cough, fever and skin rashes were the most frequently reported adverse events by the patients. Intensive efforts are required to improve adherence, as this is essential for good therapeutic outcome.

\section{REFERENCES}

1. Greener, R. AIDS and macroeconomic impact. In S, Forsyth (Ed.). State of The Art: AIDS and Economics. IAEN. 2002; pp. 49-55.

2. UNAIDS. World AIDS Day Report. 2011.

3. AIDS at 30. Nations at the crossroads. 2011

4. U.S. Global Health Policy. The global HIV/AIDS epidemics, November 11-Factsheet. 2011.

5. World Health Organization. Antiretroviral Therapy of HIV Infection in Infants and Children: Towards Universal Access. Geneva: World Health Organization 2006; Available from:

http://www.who.int/hiv/pub/guidelines/paediatric0 20907.pdf. Accessed October 22, 2011.

6. Jordan R, Gold L, Cummins C, Hyde C. Systematic review of meta-analysis of evidence for increasing numbers of drugs in antiretroviral combination therapy. BMJ 2002; 324(7340):757

7. d'Arminio Monforte A, Lepri AC, Rezza G, Pezzoti P, Antinori A, Phillips AN, et al. Insights into the reasons for discontinuation of the first highly active antretroviral therapy (HAART) regimen in a cohort of antiretroviral naove patients: Italian cohort of antiretroviral Naove patients. AIDS 2000; 14:499-507.

8. Lucas GM, Chaisson RE, Moore RD. Highly active antiretroviral therapy in a large urban clinic: Risk factors for virologic failure and adverse drug reactions. Ann Intern Med 1999; 131:81-7.

9. Montessori V, Press N, Harris M, Akagi L, Montaner JSG. Adverse effects of antiretroviral therapy for HIV infection. Can Med Assoc J. 2004; 170 (2): 229-238.

10. Duval X, Journot V, Leport C, Chêne G, Dupon M, Cuzin L, May T, Morlat P, Waldner A, Salamon R, Raffi F. Antiprotease Cohort (APROCO) Study Group: Incidence of and risk factors for adverse drug reactions in a prospective cohort of HIV infected adults initiating protease inhibitor containing therapy. Infectious Dis Soc Am. 2004; 39:248-255.

11. World Health Organization. Pharmacovigilance for antiretrovirals in resource poor countries. Medicines policy and standards. WHO Geneva reports. 2008.

12. Sharma A, Vora R, Modi M, Sharma A, Marfatia Y. Adverse effects of antiretroviral treatment. Indian J Dermatol Venereol Leprol 2008; 74: 234237.

13. Subbaraman R, Chaguturu SK, Mayer KH, Flanigan TP, Kumarasamy N. Adverse effects of highly active antiretroviral therapy in developing countries. Clin Infectious Dis. 2007; 45:1093-1101. 
14. Reust CE. Common adverse effects of antiretroviral therapy for HIV disease. Am Fam Physician 2011; 83(12):1443-1451.

15. Palella FJ, Delaney KM, Moorman AC, Loveless MO, Fuhrer J, Satten GA, Aschman DJ, Holmberg SD. (1998) Declining morbidity and mortality among patients with advanced human imunodeficiency virus infection. HIV outpatient Study Investigators. N Engl J Med, 338:853-860.

16. Laurent C, Bourgeois A, Mpoudi-Ngolé E, Ciaffi L, Kouanfack C, Mougnutou R, Nkoué N, Calmy A, Koulla-Shiro S, Delaporte E. Tolerability and effectiveness of first line regimens combining nevirapine and lamivudine plus zidovudine or stavudine in Cameroon. AIDS Res Human Retroviruses. 2008; 24 (Suppl 3):393-399.

17. Pollard RB, Robinson P, Dransfield K. Safety profile of nevirapine, a non-nucleoside reverse transcriptase inhibitor for the treatment of human immunodeficiency virus infection. Clin Ther 1998; 20:1071-1092.

18. de Maat MM, ter Heine R, van Gorp EC, Mulder JW, Mairuhu AT, Beijnen JH. Case series of acute hepatitis in a non-selected group of HIV-infected patients on nevirapine containing antiretroviral treatment. AIDS 2003; 17: 2209-2214.

19. Martínez E, Blanco JL, Arnaiz JA, Pérez-Cuevas JB, Mocroft A, Cruceta A, Marcos MA, Milinkovic A, García-Viejo MA, Mallolas J, Carné X, Phillips A, Gatell JM. Hepatotoxicity in HIV infected patients receiving nevirapine containing antiretroviral therapy. AIDS 2001; 15: 1261-1268.

20. Sulkowski MS, Thomas DL, Mehta SH, Chaisson RE, Moore RD. Hepatotoxicity associated with nevirapine or efavirenz containing antiretroviral therapy: role of hepatitis $\mathrm{C}$ and $\mathrm{B}$ infections. Hepatology 2003; 1:35.

21. Southern African HIV Clinicians Society. Fixeddose combination for adults accessing antiretroviral therapy. S Afr J HIV Med 2013; 14(1 Suppl):41-43.

22. Rather ZA, Chowta MN, Prakash Raju G, Mubeen F. Evaluation of the adverse reactions of antiretroviral drug regimens in a tertiary care hospital. Indian J Pharmacol 2013; 45 (2):145-148.

23. Keiser O, Fellay J, Opravil M, et al. Adverse events to antiretrovirals in the Swiss HIV Cohort Study: effect on mortality and treatment modification. Antivir Ther 2007; 12 (8): 1157-1164.

24. Bersoff-Matcha SJ, Miller WC, Aberg JA, et al. Sex differences in nevirapine rash. Clin Infect Dis 2001; 32 (1): 124-129.

25. Fagot JP, Mockenhaupt M, Bouwes-Bavinck J-N, for the EuroSCAR study group. Nevirapine and the risk of Stevens- Johnson syndrome or toxic epidermal necrolysis. AIDS 2001; 15(14):1843-1848.

26. Moyle GJ, Datta D, Mandalia S, et al. Hyperlactataemia and lactic acidosis during antiretroviral therapy: relevance, reproducibility and possible risk factors. AIDS 2002; 16(10):1341-1349.

27. Bolhaar MG, Karstaedt AS. A high incidence of lactic acidosis and symptomatic hyperlactatemia in women receiving highly active antiretroviral therapy in Soweto, South Africa. Clin Infect Dis 2007; 45(2):254-260.

28. Dieterich DT, Robinson PA, Love J, Stern JO. Drug-induced liver injury associated with the use of nonnucleoside reverse-transcriptase inhibitors. Clin Infect Dis 2004; 38(Suppl 2):S80-89.

29. Saag M, Balu R, Phillips E, et al. High sensitivity of human leukocyte antigen-b*5701 as a marker for immunologically confirmed abacavir hypersensitivity in white and black patients. Clin Infect Dis 2008; 46(7):1111-1118.

30. WHO/Forum for Collaborative HIV Research Joint Meeting. ARV Drugs Adverse Events, Case Definition Grading, Laboratory Diagnosis and Treatment Monitoring. Available from: ww.hivforum.org 2008. Accessed October 22, 2011

31. Raosoft ${ }$ Sample Size Calculator. Available at: http://www.raosoft.com/samplesize.html. Accessed 17 July 2013.

32. Federal Ministry of Health, Abuja, Nigeria. National Guideline for HIV and AIDS Teatment and Care in Adolescents and Adults. 2009.

33. Arnsten JH, Demas PA, Farzadegan H, Grant RW, Gourevitch MN, Chang CJ, Buono D, Eckholdt H, Howard AA, Schoenbaum EE. Antiretroviral therapy adherence and viral suppression in HIVinfected drug users: comparison of self-report and electronic monitoring. Clin Infect Dis; 2001; 33(8):1417-23.

34. European guidelines for the clinical management and treatment of HIV-infected adults in Europe. AIDS Report 2003; 17 (Suppl 2):3-26.

35. Ford N, Mofenson L, Kranzer K, Medu L, Frigati L, Mills E. J, Calmy A. Safety of efavirenz in firsttrimester of pregnancy: A systematic review and meta-analysis of outcomes from observational cohorts". AIDS 2010; 24 (10): 1461-1470.

36. UNAIDS. UNAIDS report on the global AIDS epidemic. 2010.

37. NACA. Update on the HIV/AIDS Epidemic and Response in Nigeria. Fact Sheets (2011) http://naca.gov.ng/content/view/423/lang,en/\#profi le,

38. Ledergerber B, Egger M, Opravil M, Telenti A, Hirschel B, Battegay M. Clinical progression and 
virological failure on highly active antiretroviral therapy in HIV-1 patients: a prospective cohort study. Lancet 1999; 353: 863-868

39. Haubrich R, Demeter L. International perspectives on antiretroviral resistance. Clinical utility of resistance genotyping: retrospective and prospective data supporting use and current recommendations. J Acquir Immune Defic Syndr. 2001; 26: S51-S59.

40. Max, B. and R. Scherer. Management of the adverse effects of antiretroviral therapy and medication adherence. Clinical Infectious Diseases 2000; 30: S96-S116.

41. Gautam H, Bhalla P, Saini S, Dewan R. Correlation between baseline $\mathrm{CD}^{+}$t-lymphocyte count and plasma viral load in AIDS patient and their early clinical and immunological response to HAART: A Preliminary Study. Indian $J$ Med Microb. 2008; 26 (3): 256-58

42. Aidsmap. Abacavir linked to heart disease, stroke, tenofovir to heart failure, in large US study. AIDS 2011; 22 (14).

43. Liverpool HIV Pharmacology Group [database on the Internet]. Cheshire, United Kingdom: The University of Liverpool and eMedFusion 2010; Available from: www.hiv-druginteractions.org. Accessed December 1, 2012. 